\title{
ON THE USE OF THE EQUILIBRIUM EQUATIONS AND FLOW LAW IN RELATING THE SURFACE AND BED TOPOGRAPHY OF GLACIERS AND ICE SHEETS
}

\author{
By I. F. Collins \\ (Department of Applied Mathematics and Theoretical Physics, University of Cambridge, \\ Cambridge, England)
}

\begin{abstract}
In a recent paper Robin has developed a method of calculating the relation between bed and surface topography of an ice sheet. He found that by including the effect of longitudinal strains in the equilibrium equation the correlation between theory and observation could be much improved. This paper is concerned with the mathematical justification of the assumption made by Robin.
\end{abstract}

RÉsumÉ. Sur la relation entre la topographie superficielle et celle du socle rocheux d'un indlandsis. Dans une récente publication, Robin a développé une méthode de calcul de la relation entre la topographie superficielle et celle du socle rocheux d'un indlandsis. Il a trouvé qu'en introduisant l'effet de deformations longitudinales dans l'équation d'équilibre, la corrélation entre la théorie et l'observation pouvait être bien améliorée. Le présent rapport constitue la justification mathématique des hypothèses faites par Robin.

Zusammenfassung. Über den Zusammenhang zwischen der Oberfächen- und Untergrundstopographie von Eisschilden. In einer neueren Arbeit hat Robin eine Methode zur Berechnung des Zusammenhanges zwischen Untergrunds- und Oberflächentopographie eines Eisschildes entwickelt. Er fand, dass bei Berücksichtigung der Wirkung von Längsverzerrung in der Gleichgewichtsbedingung die Übereinstimmung zwischen Theorie und Beobachtung stark verbessert werden kann. Diese Arbeit ist auf die mathematische Begründung von Robins Annahme gerichtet.

\section{INTRODUCTION}

This paper is complementary to a paper by Robin (1967) concerning the flow of an ice sheet over an uneven bed, and in particular the relation between bed and surface topography. Until recently a simple pseudo-hydrostatic theory due to Nye (1952) has been in sufficient agreement with observation as not to warrant any refinement in the theory. However, recent improvements in observational precision using continuous radio-echo sounding techniques have shown discrepancies between observation and this theory. Similar discrepancies have been previously noted by Lliboutry (1958, I 964-65) from data obtained on the Mer de Glace.

In his paper Robin shows that by taking into account the "longitudinal stresses" set up by the flow of ice over protuberances on the bed, the correlation between theory and observation can be much improved. The present paper is concerned with the mathematical justification of Robin's approach.

In section 2 an exact statement of the quasi-static equilibrium of the ice is derived in an integrated form. Two related assumptions are then made to reduce the problem to a readily tractable one-dimensional one. The relation between longitudinal stress (which is given a precise meaning) and strain-rate is derived in section 3, and the validity of the assumptions made is discussed in section 4 .

\section{The Quasi-state Equilibrium of an Ice Sheet}

Consider the two-dimensional (plane-strain) flow of ice over an uneven bed (Fig. I). Take orthogonal cartesian axes $\mathrm{O} x, \mathrm{O} y$ in the horizontal and vertical directions, $\mathrm{O} x$ being an arbitrarily chosen horizontal datum line. (An alternative scheme would be to take local orthogonal axes with one axis in the local direction of the bed or surface. The resulting integrated form of the equilibrium equations are then symbolically simpler, but have the disadvantage of being referred to axes which are curvilinear and may be initially unknown.) 


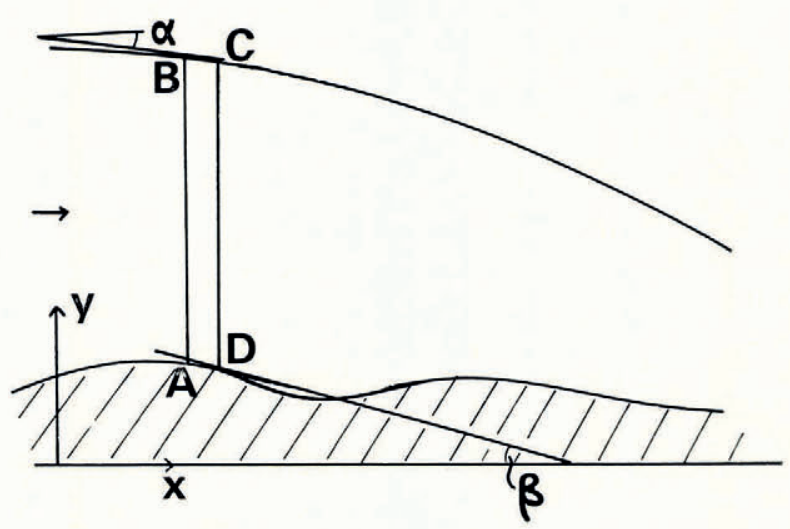

Fig. 1. Nomenclature

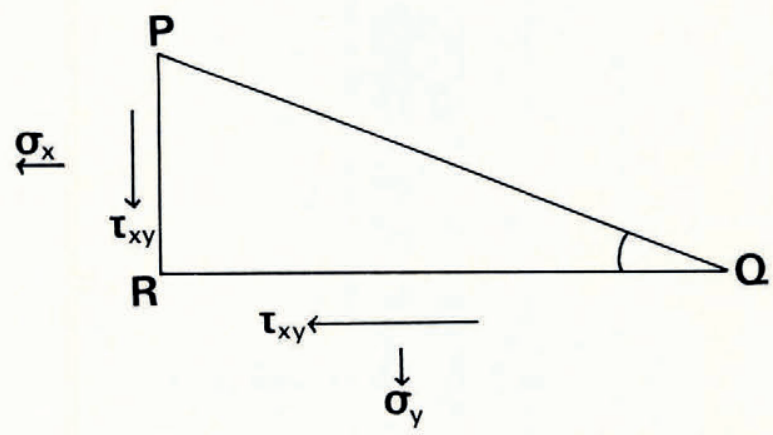

Fig. 2. Infinitesimal triangle in the surface

The differential forms of the equilibrium equations (neglecting inertia) are, in the $x$ and $y$ directions respectively,

and

$$
\begin{gathered}
\frac{\partial \sigma_{x}}{\partial x}+\frac{\partial \tau_{x y}}{\partial y}=0 \\
\frac{\partial \sigma_{y}}{\partial y}+\frac{\partial \tau_{x y}}{\partial x}-\rho g=0
\end{gathered}
$$

where $\sigma_{x}, \sigma_{y}$ are the normal components and $\tau_{x y}$ the shear component of stress and $\rho$ the density of ice (assumed uniform).

The shear stress on the bed we shall denote by $T$. On the surface the normal and shear tractions are both zero; it is convenient to express these conditions in terms of the stress components referred to the $(x, y)$ coordinate system. Consider the equilibrium of the infinitesimal triangle PQR shown in Figure 2, PQ lies in the surface and is hence stress free. Resolving in the $x$ and $y$ directions we obtain

but

$$
\sigma_{x} \mathrm{PR}+\tau_{x y} \mathrm{QR}=\mathrm{o}, \quad \sigma_{y} \mathrm{QR}+\tau_{x y} \mathrm{PR}=\mathrm{o},
$$

therefore

$$
\mathrm{PR} / \mathrm{QR}=\tan \alpha=-\mathrm{d} h_{\mathrm{s}} / \mathrm{d} x=-h_{\mathrm{s}}^{\prime},
$$

where $h_{\mathrm{s}}$ is the vertical height of the surface above the datum and $\alpha$ the inclination of the surface to the horizontal.

An integrated form of one of the equilibrium equations can be obtained by considering the equilibrium of the region $A B C D$ in Figure $\mathrm{I}$. Resolving parallel to the bed so as to avoid the large, unknown normal traction of the bed, 


$$
\mathcal{T} \sec \beta-\rho g h \sin \beta=\cos \beta \frac{\partial}{\partial x} \int_{h_{\mathrm{b}}}^{h_{\mathrm{s}}} \sigma_{x} \mathrm{~d} y-\sin \beta \frac{\partial}{\partial x} \int_{h_{\mathrm{b}}}^{h_{\mathrm{s}}} \tau_{x y} \mathrm{~d} y
$$

where $\beta$ is the slope of the bed, $h_{\mathrm{b}}, h_{\mathrm{s}}$ are the heights of the bed and surface above the datum and $h=h_{\mathrm{s}}-h_{\mathrm{b}}$ is the vertical ice thickness.

It is reasonably well established (e.g. Nye, r 959) that the flow of ice is not affected by hydrostatic pressure, and hence in any flow law the normal strain-rates must be related to the deviatoric components of normal stress (i.e. normal stress less the hydrostatic stress). We cannot then relate $\sigma_{x}$ as it occurs in Equation (4) to the strain-rates, but must first eliminate the hydrostatic component. This is done below by using the vertical equilibrium equation to express $\frac{\partial}{\partial x} \int_{h_{\mathrm{b}}}^{h_{s}} \sigma_{y} \mathrm{~d} x$ in terms of the shear stress and boundary tractions, and then combining this with Equation (4) so that the right-hand side is replaced by terms independent of the hydrostatic pressure.

Consider

$$
\frac{\partial^{2}}{\partial x^{2}} \int_{h_{\mathrm{b}}}^{h_{\mathrm{s}}} y \tau_{x y} \mathrm{~d} y \equiv \frac{\partial}{\partial x} \int_{h_{\mathrm{b}}}^{h_{\mathrm{s}}} y \frac{\partial \tau_{x y}}{\partial x} \mathrm{~d} y+\frac{\partial}{\partial x}\left[\left.h_{\mathrm{s}} h_{\mathrm{s}}^{\prime} \tau_{x y}\right|_{\mathrm{s}}-\left.h_{\mathrm{b}} h_{\mathrm{b}}^{\prime} \tau_{x y}\right|_{\mathrm{b}}\right]
$$

performing the first differentiation with respect to $x$ (the suffixes " $\mathrm{s}$ " and " $b$ " signify that the stress component is evaluated on the surface and bed respectively). Substituting for $\partial \tau_{x y} / \partial x$ from the second equilibrium equation and making use of the surface boundary conditions (3),

$$
\frac{\partial^{2}}{\partial x^{2}} \int_{h_{\mathrm{b}}}^{h_{\mathrm{s}}} y \tau_{x y} \mathrm{~d} y=\frac{\partial}{\partial x}\left[\frac{\mathrm{I}}{2} \rho g\left(h_{\mathrm{s}}^{2}-h_{\mathrm{b}}^{2}\right)-\int_{h_{\mathrm{b}}}^{h_{\mathrm{s}}} y \frac{\partial \sigma_{y}}{\partial y} \mathrm{~d} y+\left.h_{\mathrm{s}} \sigma_{y}\right|_{\mathrm{s}}-\left.h_{\mathrm{b}} h_{\mathrm{b}}^{\prime} \tau_{x y}\right|_{\mathrm{b}}\right],
$$

and, using the formula for integration by parts,

$$
=\frac{\partial}{\partial x} \int_{h_{\mathrm{b}}}^{h_{\mathrm{s}}} \sigma_{y} \mathrm{~d} y+\frac{\partial}{\partial x}\left[\frac{1}{2} \rho g\left(h_{\mathrm{s}}^{2}-h_{\mathrm{b}}^{2}\right)-\left.h_{\mathrm{b}} h_{\mathrm{b}}^{\prime} \tau_{x y}\right|_{\mathrm{b}}+\left.h_{\mathrm{S}} \sigma_{y}\right|_{\mathrm{s}}\right] .
$$

Hence combining this with Equation (4) we obtain

$$
\left.\begin{array}{c}
T \sec \beta-\rho g h \sin \beta=\cos \beta \frac{\partial}{\partial x} \int_{h_{\mathrm{b}}}^{h_{\mathrm{s}}}\left(\sigma_{x}-\sigma_{y}\right) \mathrm{d} y+\cos \beta \frac{\partial^{2}}{\partial x^{2}} \int_{h_{\mathrm{b}}}^{h_{\mathrm{s}}} y \tau_{x y} \mathrm{~d} y- \\
-\sin \beta \frac{\partial}{\partial x} \int_{h_{\mathrm{b}}}^{h_{\mathrm{s}}} \tau_{x y} \mathrm{~d} y-\cos \beta \frac{\partial}{\partial x}\left[\frac{1}{2} \rho g\left(h_{\mathrm{s}}^{2}-h_{\mathrm{b}}^{2}\right)+h_{\mathrm{b}}\left(-\left.h_{\mathrm{b}}^{\prime} \tau_{x y}\right|_{\mathrm{b}}+\left.\sigma_{y}\right|_{\mathrm{b}}\right)\right]
\end{array}\right\}_{(5)^{*}}
$$

This equation is exact, depending only on the quasi-static equilibrium of the ice sheet.

We now make two related approximations (a) $\beta$ the bed slope, and hence $\alpha$ the surface slope, is small, so that we can replace $\sin \beta$ by $\beta$, etc., and (b) the shear stress component $\tau_{x y}$ is small compared with $\sigma_{x}-\sigma_{y}$ at least when averaged throughout the thickness of the ice. Equation (5) now reduces to

$$
T-\rho g h \beta=\frac{\partial}{\partial x} \int_{h_{\mathrm{b}}}^{h_{\mathrm{s}}}\left(\sigma_{x}-\sigma_{y}\right) \mathrm{d} y-\frac{\partial}{\partial x}\left[\frac{1}{2} \rho g\left(h_{\mathrm{s}}^{2}-h_{\mathrm{b}}^{2}\right)+\left.h_{\mathrm{b}} \sigma_{y}\right|_{\mathrm{b}}\right]
$$

The approximation (b) is in fact over-restrictive for the validity of Equation (6), it being only necessary for $\tau_{x y}$ to be such that the second term on the right-hand side of Equation (5)

* This way of expressing the equilibrium equation was suggested to the author by Dr R. Hill, who had obtained the corresponding equation for a plane inclined bed (unpublished) using a general technique described in Hill ( 1963$)$. 
be small in comparison with the first. However it is shown later that to relate the stresses with strain-rates calculable from known accumulation data it is necessary to make the stronger approximation made here.

From Equations (2) and (3) we see that the neglect of the $\tau_{x y}$ term implies that $-\sigma_{y}$ is equal to the weight of overlying ice. In particular on the bed $\left.\sigma_{y}\right|_{\mathrm{b}}=-\rho g h=-\rho g\left(h_{\mathrm{s}}-h_{\mathrm{b}}\right)$. This can be seen directly by considering the vertical equilibrium of the ice column ABCD in Figure I. Since we are neglecting the shear stresses on $\mathrm{AB}$ and $\mathrm{CD}$, the normal force on the bed balances the weight of the ice column. Thus the vertical normal stress component is the same as if the ice were stagnant (to the approximations of the present theory). This is not true of the horizontal normal stress component.

Combining the last term on the right-hand side with that on the left we have finally

where

$$
\begin{gathered}
T-\rho g h \alpha=\frac{\partial}{\partial x} \int_{h_{\mathrm{b}}}^{h_{\mathrm{s}}}\left(\sigma_{x}-\sigma_{y}\right) \mathrm{d} y=\frac{\partial F}{\partial x} \\
F=\int_{h_{\mathrm{b}}}^{h_{5}}\left(\sigma_{x}-\sigma_{y}\right) \mathrm{d} y=h\left(\bar{\sigma}_{x}-\bar{\sigma}_{y}\right)
\end{gathered}
$$

(bars denoting quantities averaged throughout the ice thickness). Notice that the slope occurring in Equation (7) is the surface and not the bed slope. The argument presented above shows that this fact can be attributed to the need to eliminate hydrostatic pressure from Equation (4), and it would not follow if ice were a compressible material.

If further we assume $\sigma_{x}-\sigma_{y}$ is negligible, so that both $\sigma_{x}$ and $\sigma_{y}$ are equal to the hydrostatic stress, then we have Nye's pseudo-hydrostatic theory

$$
T=\rho g h \alpha .
$$

If we can assume $T$ is constant along the bed, then the ice thickness is inversely proportional to the surface slope (Nye, I952). Alternatively we could use the law of sliding, in which the longitudinal velocity $u$ is assumed constant with depth, and is related to the shear stress on the bed by a power law (Weertman, r957; Nye, r959)

$$
u=(T / B)^{m}
$$

where $B, m$ are constants, $m=(n+\mathrm{I}) / 2$ where $n$ is the power in Glen's law. The relation between ice thickness and surface slope based on Equations (9) and (10) is derived by Nye (1959).

The present theory differs from Nye's in the inclusion of the "longitudinal force" $F$ in the equilibrium equation (7). The importance of this effect was first noted by Orowan (I949) who, however, only considered the basic equilibrium equation (4). In his analysis of Vallot's data from the Mer de Glace, Lliboutry did in fact use Equation (7); he did not, however, prove this equation rigorously or investigate the conditions for its validity.

In order to relate this additional force with the longitudinal strain-rate, use must be made of the flow law.

\section{Use of the Flow Law}

Nye's generalization of Glen's law can be written (as in Nye, 1957)

$$
\dot{\epsilon}=(\tau / A)^{n}
$$

where $A, n$ are constants, $n \approx 4$ and $\dot{\epsilon}, \tau$ are the second invariants of the strain-rate and stress-deviator tensors respectively, defined by

and

$$
\begin{gathered}
\dot{\epsilon}^{2}=\left(\dot{\epsilon}_{x}-\dot{\epsilon}_{y}\right)^{2}+4 \dot{\epsilon}_{x y}^{2} \\
\tau^{2}=\left(\sigma_{x}-\sigma_{y}\right)^{2}+4 \tau_{x}^{2} y .
\end{gathered}
$$

The individual tensor components are related by

$$
\dot{\epsilon}_{x}=\lambda \sigma_{x}^{\prime}, \quad \dot{\epsilon}_{y}=\lambda \sigma_{y}^{\prime}, \quad \dot{\epsilon}_{x y}=\lambda \tau_{x y}
$$


where $\sigma_{x}^{\prime}, \sigma_{y}^{\prime}$ are the normal stress deviators and $\lambda=\tau^{n-1} / A^{n}$ for consistency with Equation (I I). The normal strain-rate components also satisfy the incompressibility conditions

$$
\dot{\epsilon}_{x}+\dot{\epsilon}_{y}=\mathrm{o}
$$

We now make the assumption that the shear components of strain-rate are small in comparison with the normal strain-rates when averaged throughout the thickness of the ice (more precisely $\overline{\partial u / \partial y}, \overline{\partial v / \partial x} \ll \overline{\partial u / \partial x}, \overline{\partial v / \partial y}$ ). This is the same as assumption (b) in section 2. In which case Equations (12) and (13) reduce (when averaged) to:

$$
\overline{\dot{\epsilon}}=\overline{\dot{\epsilon}}_{x}-\overline{\dot{\epsilon}}_{y}, \quad \bar{\tau}=\bar{\sigma}_{x}-\bar{\sigma}_{y}
$$

Thus from Equations (I I) and (I5)

$$
\overline{\dot{\epsilon}}_{x}=-\overline{\dot{\epsilon}}_{y}=\frac{1}{2}\left[\left(\bar{\sigma}_{x}-\bar{\sigma}_{y}\right) / A\right]^{n}
$$

where we have further assumed that $\tau$ or equivalently $\dot{\epsilon}_{x}=\partial u / \partial x$ is constant with depth so that we can equate $\bar{\tau}^{n}$ with $\overline{\tau^{n}}$. This follows from our neglect of shear strain-rate, for if $\partial u / \partial y \approx 0$ everywhere then $\partial^{2} u / \partial x \partial y \approx 0$, i.e. $\partial \dot{\epsilon}_{x} / \partial y \approx 0$. The value of $\dot{\epsilon}_{x}$ can then be expressed in terms of accumulation distribution and surface velocity by considering the conservation of mass in ABCD (Fig. I)

$$
\frac{\partial}{\partial x} \int_{h \mathrm{~b}}^{h_{\mathrm{s}}} u \mathrm{~d} y=\int_{h_{\mathrm{b}}}^{h_{\mathrm{s}}} \frac{\partial u}{\partial x} \mathrm{~d} y+\left.u\right|_{\mathrm{s}} h_{\mathrm{s}}^{\prime}-\left.u\right|_{\mathrm{b}} h_{\mathrm{b}}^{\prime}=\dot{a}
$$

where $\dot{a}$ is the accumulation rate. Again invoking the assumption that $\partial u / \partial y \approx 0$ so that $\left.\left.u\right|_{\mathrm{s}} \approx u\right|_{\mathrm{b}}$, we have

$$
\overline{\dot{\epsilon}}_{x}=\frac{\mathrm{I}}{h}\left(a-u h^{\prime}\right)
$$

From estimated values of $\dot{a}$ and $u$ and measured values of $h$ and $h^{\prime}, \overline{\dot{\epsilon}}_{x}$ is given by Equation (1 7) and hence $\sigma_{x}-\sigma_{y}$ from Equation (I6), $F$ from Equation (8) and the necessary modification to the surface slope from Equation (7). For details of the calculations the reader is referred to Robin's paper (1967).

\section{Summary}

The two approximations necessary for the application of Robin's method are as stated in section 2 :

(a) the bed slope $\beta$ is small,

(b) the shear stress component $\tau_{x y}$ is small compared with the normal stress difference when averaged throughout the ice thickness.

Assumption (b) is a sufficient condition for the use of the approximate equilibrium equation (7). It is both necessary and sufficient for the application of the flow law in the simplified form of Equation (I6). This approximation will hold if the motion of the ice consists entirely of basal slip, the longitudinal velocity being constant with depth, and the only internal deformation occurring being longitudinal straining. This is the assumption Nye makes in his sliding model of glacier motion. However, it is not justified to neglect the $\partial F / \partial x$ term in the equilibrium equation, as Nye (1959) does, if this term is comparable with $T$, the relative importance of these two terms must be estimated in each case considered.

The effect of making approximations (a) and (b) is to reduce the problem to an essentially one-dimensional one. If these approximations are relaxed it becomes necessary to solve a two-dimensional boundary-value problem. This latter problem is considerably more difficult and laborious to solve. 
Acknowledgements

This work was supported by a research grant from the Science Research Council. The author would like to thank Dr R. Hill, F.R.S., Dr G. de Q. Robin and Dr J. F. Nye for helpful comments on this paper.

$M S$. received 28 fuly 1967 and in revised form 24 October 1967

\section{REFERENCES}

Hill, R. 1963. A general method of analysis for metal-working processes. Journal of the Mechanics and Physics of Solids, Vol. 11, No. 5, p. 305-26.

Lliboutry, L. 1958. La dynamique de la Mer de Glace et la vague de 189i-95 d'après les mesures de Joseph Vallot. Union Géodésique et Géophysique Internationale. Association Internationale d'Hydrologie Scientifique. Symposium de Chamonix, $16-24$ sept. 1958 , p. 125-38.

Lliboutry, L. 1964-65. Traité de glaciologie. Paris, Masson et Cie. 2 vols.

Nye, J. F. 1952. A method of calculating the thicknesses of the ice-sheets. Nature, Vol. 169, No. 4300, p. 529-30.

Nye, J. F. 1957. The distribution of stress and velocity in glaciers and ice-sheets. Proceedings of the Royal Society Ser. A, Vol. 239, No. 1216, p. I13-33.

Nye, J. F. 1959. The motion of ice sheets and glaciers. Fournal of Glaciology, Vol. 3, No. 26, p. 493-507.

Orowan, E. 1949. The flow of ice and of other solids (In "Joint meeting of the British Glaciological Society, the British Rheologists' Club and the Institute of Metals", Fournal of Glaciology, Vol. I, No. 5, p. 23I-40.)

Robin, G. de Q. 1967 . Surface topography of ice sheets. Nature, Vol. 21 5, No. 5105, p. 1029-32.

Weertman, J. 1957. On the sliding of glaciers. Fournal of Glaciology, Vol. 3, No. 21, p. 33-38. 